DOSSIÊ TEMÁTICO: Formação Docente, Práticas Pedagógicas e Relações Raciais e de Gênero

do] https://doi.org/10.22481/praxisedu.v16i39.6362

\title{
AFRICANIDADES E TRIBALISMO CULTURAL: EXPERIENCIAS DE PROFESSORES (AS) DA CIDADE AFRICANA DE OBUASI, GHANA
}

\author{
AFRICANIDADES AND CULTURAL TRIBALISM: EXPERIENCES OF TEACHERS \\ FROM THE AFRICAN CITY OF OBUASI, GHANA
}

\begin{abstract}
AFRICANIDADES Y TRIBALISMO CULTURAL: EXPERIENCIAS DE PROFESORES DE LA CIUDAD AFRICANA DE OBUASI, GHANA
\end{abstract}

Silvani dos Santos Valentim

Centro Federal de Educação Tecnológica de Minas Gerais - Brasil

Jane Moreira

Centro Federal de Educação Tecnológica de Minas Gerais - Brasil

\begin{abstract}
Resumo: Este artigo apresenta dimensões de um estudo que se ateve às experiências pedagógicas de um grupo de professores (as) de escolas públicas de Obuasi, Ghana, na África Ocidental. O objetivo é apresentar as especificidades das experiências dos (as) professores (as), por meio de uma abordagem informativa, analítica e reflexiva das relações tribais culturais no espaço escolar, da valorização identitária dos povos de Ghana, da importância da educação bilíngue, do desafio de ser professora ou professor em uma escola com pessoas falantes de diversos idiomas, com conhecimentos prévios distintos e expectativas em relação à educação escolarizada. A metodologia envolveu etnografia virtual. Dada a singularidade da pesquisa realizada, utilizou-se tecnologias digitais, ambiente virtual, e aplicativo de mensagens. A primeira parte do estudo ocorreu quando professores (as) de Obuasi foram á cidade de Sabará, em Minas Gerais, Brasil, para uma troca de experiência na cidade que reconheceram ser uma cidade irmã. Neste artigo tratamos da segunda parte da troca de experiências, quando os professores de Ghana, após retornarem ao seu país, iniciaram um diálogo com as autoras do presente artigo. Que este estudo possa fortalecer os projetos, reflexões e intervenções promovidas pela Educação das Relações Raciais e as africanidades brasileiras. Este estudo caracterizou-se por ser uma construção a partir da vivencia compartilhada, que se assemelhou ao processo de tecer uma das tiras do tecido Kente, de Ghana. Nesse entrelaçar é preciso continuar a tecer até completar o tecido do conhecimento, que segue sempre demandando mais tecituras.
\end{abstract}

Palavras chave: Tribalismo cultural. Africanidades. Experiências docentes.

Abstract: This article presents dimensions of a study that focused on the pedagogical experiences of a group of teachers from public schools in Obuasi, Ghana, in West Africa. The objective is to present the specificities of the teachers' experiences, by means of an informative, analytical and reflective 
approach to the cultural tribal relations in the school arena, the valorization of the identity of the people of Ghana, the importance of bilingual education, the challenge of being a teacher in a school with people who speak different languages, with different prior knowledge and expectations regarding school education. The methodology involved virtual ethnography. Given the uniqueness of the research, digital technologies, a virtual environment, and a messaging application were used. The first part of the study took place when teachers from Obuasi went to the city of Sabará, in Minas Gerais, Brazil, to exchange experiences in the city that they recognized as a sister city. In this article we deal with the second part of the exchanging experience. After returning to their country the teachers from Ghana started a dialogue with the authors of this article. May this study strengthen the projects, reflections and interventions promoted by an Education for Race Relations and Brazilian Africanidades. This study characteristic is to be built on shared experience, which was similar to the process of weaving one of the strips of Kente fabric, from Ghana. In this interweaving, it is necessary to continue weaving until the fabric of knowledge is completed, which always demands more weaving.

Key words: Cultural tribalism.Africanidades. Teachers experiences

Resumen: Este artículo presenta las dimensiones de un estudio que se centró en las experiencias pedagógicas de un grupo de docentes de escuelas públicas en Obuasi, Ghana, en África occidental. El objetivo es presentar las especificidades de las experiencias de los docentes, a través de un enfoque informativo, analítico y reflexivo sobre las relaciones tribales culturales en el espacio escolar, la valoración de la identidad de la gente de Ghana, la importancia de la educación bilingüe, el desafío de ser maestro o maestro en una escuela con personas que hablan diferentes idiomas, con diferentes conocimientos previos y expectativas con respecto a la educación escolar. La metodología involucraba etnografía virtual. Dada la singularidad de la investigación, se utilizaron tecnologías digitales, un entorno virtual y una aplicación de mensajería. La primera parte del estudio tuvo lugar cuando los maestros de Obuasi fueron a la ciudad de Sabará, en Minas Gerais, Brasil, para un intercambio de experiencias en la ciudad que reconocieron como una ciudad hermana. En este artículo abordamos la segunda parte del intercambio de experiencias, cuando los maestros de Ghana, después de regresar a su país, comenzaron un diálogo con los autores de este artículo. Que este estudio fortalezca los proyectos, reflexiones e intervenciones promovidas por la Educación para las Relaciones Raciales y las africanidades brasileñas. Este estudio se caracterizó por ser una construcción basada en experiencias compartidas, que fue similar al proceso de tejer una de las tiras de tela Kente, de Ghana. En este entretejido, es necesario continuar tejiendo hasta que se complete el tejido del conocimiento, lo que siempre exige más tejido.

Palabras clave: tribalismo cultural. Africanidades. Experiencias docentes.

\section{Introdução}

As africanidades e as heranças afrodescendentes ainda são temas que carecem de aprofundamento na sociedade brasileira e na educação em suas diferentes modalidades, inclusive na educação básica. Em abordagem sobre o assunto, a professora e pesquisadora Silva (2003), traz uma definição de africanidades, evidenciando a contribuição africana na sociedade brasileira. 
A expressão africanidades brasileiras refere-se às raízes da cultura brasileira que têm origem africana. Dizendo de outra forma, queremos nos reportar ao modo de ser, de viver, de organizar suas lutas, próprio dos negros brasileiros e, de outro lado, às marcas da cultura africana que, independentemente da origem étnica de cada brasileiro, fazem parte do seu dia a dia. (SILVA, 2003, p.2).

Neste sentido, este estudo reconhece uma forma de africanidade em África, mas especificamente em Ghana ${ }^{1}$, que intitulamos tribalismo cultural. Esta pesquisa analisou as experiências didáticas e pedagógicas vivenciadas por professores (as) de Obuasi, Ghana. Estas experiências foram relatadas por intermédio das postagens de suas práticas escolares em vídeos, aplicativos de mensagens e fotos, de forma virtual e através de um grupo criado em um aplicativo de mensagens, tendo sido utilizadas tecnologias digitais para a aproximação e diálogo com os (as) professores (as) de Ghana. Em 2018 foi realizado o estudo que envolveu um grupo de seis professores (as) de escolas públicas de Obuasi (ver quadro I nos parágrafos seguintes). Os professores (as) estavam na faixa etária entre 25 e 48 anos e utilizaram as ferramentas de comunicação à distância com destreza e entusiasmo. A Internet possibilitou a integração entre os participantes do estudo e entre os pesquisadores e os participantes. Os participantes falavam línguas locais diferentes sendo o inglês o idioma de comunicação e o ofício de professor (a) o elemento unificador na busca de uma linguagem, de uma tradução e comunicação constante dos significados do ser docente em Obuasi. As novas tecnologias trazem mudanças e contribuições significativas para pesquisas em educação. No caso em tela, podemos citar o conhecimento da realidade educacional de Obuasi de forma simultânea, já que, diversas postagens eram feitas em tempo real. Por meio de hangouts2, filmagem das aulas, o recreio, as apresentações, oportunizando uma vivencia virtual.

Este artigo apresenta dimensões do sistema educacional da cidade mineradora de Obuasi3 em Ghana4, no que concerne o tribalismo cultural na prática pedagógica. O tribalismo cultural vivenciado pelos (as) professores (as) de Obuasi está presente no contexto

\footnotetext{
${ }^{1}$ Muitos africanos traficados como escravos voltaram para Ghana na década de 1830, depois da Revolta dos Malês, na Bahia.

2 Google Hangouts é uma plataforma de comunicação, desenvolvida pela Google, que inclui mensagens instantâneas, chat de vídeo, SMS e VOIP. Foi lançada em 15 de maio de 2013, durante a conferência de desenvolvedores Google I/O

3 Cidade mineradora, grande produtora de ouro, localizada a $250 \mathrm{~km}$ da capital de Ghana Accra.

4 País localizado na África Ocidental, capital Accra, atual República de Ghana, A denominação Ghana foi adotada no governo de Kwamé Nkrumah (1909-1972), líder político africano e um dos fundadores do Pan Africanismo (uma ideologia que propõe a união de todos os povos da África como forma dar visibilidade ao continente no contexto internacional). Foi primeiro-ministro entre 1957 e 1960 e presidente de Ghana de 1960 a 1966. Trabalhou para a descolonização da África e para rebatizar a antiga Colônia Britânica da Costa do Ouro com uma referência africana.
} 
escolar, desafiando os (as) docentes a construírem uma educação capaz de lidar com as especificidades tribais. Segundo relato das professoras e professores, até o ano de 2016, as escolas não trabalhavam a questão do tribalismo, porém ao término do ano letivo, em julho de 20165 , e início de 2017 alguns professores coordenadores pediram que essa questão fosse introduzida nas práticas pedagógicas para promoção de uma educação mais igualitária no município.

As atividades referentes ao tribalismo não são regulamentadas por lei, os professores iniciaram práticas pedagógicas para promover relações educacionais tribais a partir da percepção de que o tribalismo cultural deve ser positivo na construção de uma escola para todos (as). Os (as) professores (as) participantes estavam a buscar diretrizes que valorizassem a origem de cada grupo e dialogassem com os pertencimentos dos demais grupos, sem que alguns ficassem em posição de destaque sobre os demais. Dentro disso, a convivência amigável entre os alunos às vezes se limitava a não se provocarem e ou evidenciarem as diferenças, se respeitando, mas não chegando a criar um ambiente de solidariedade, no qual as pessoas conversassem entre si, compartilhassem experiências, se ajudassem no que fosse necessário. Uma intervenção a partir do tribalismo cultural foi reconhecida como uma importante estratégia para modificar esta realidade.

Os (as) professores (as) pesquisados (as) preservam as roupas, as comidas, as músicas, os rituais de passagem e as honras familiares de suas respectivas tribos. Todos (as) os (as) professores (as) participantes da pesquisa sabem dizer a qual grupo étnico pertencem, o dia da semana no qual nasceram ${ }^{6}$, o seu nome tribal, assim como outros aspectos específicos de cada pessoa. No momento em que se apresentam, em situações de socialização e dinâmicas, dizem o nome e logo em seguida informam o grupo étnico. Por exemplo: “eu, 'fulana de tal', sou Ashanti”, "eu sou Ga", logo em seguida dizem o cargo ocupado no espaço escolar. Eles permanecem Gonja, Ewe, Ashanti, Ga, Fante, dentre outros grupos étnicos de Ghana. A auto afirmação tribal é simultânea ao cargo ocupado na escola ou função na sociedade. Ou seja, a pertença a uma tribo é um elemento que vai além do espaço de residência, das rotinas estabelecidas, e das honras familiares.

O quadro I apresenta uma breve descrição dos (as) professores (as) do Distrito de Obuasi, sua atuação, tempo de magistério e formação acadêmica.

$5 \mathrm{O}$ ano letivo em Obuasi inicia em setembro e finda em julho do ano seguinte, portanto o $1^{\circ}$ semestre de 2017 iniciou-se em setembro de 2016.

6 A data de nascimento e o dia da semana definem a origem do nome da criança, diversos professores possuem o nome dado pela tribo e o nome de "registro". Podemos citar a professora Abigail Quagrane que nasceu em 18/05 e a data foi uma terça-feira, que para ela tem um significado, sendo às terças-feiras o seu dia de referência. 
Quadro I - Professores do Distrito de Obuasi

\begin{tabular}{|c|c|c|c|c|c|}
\hline Professor (a) & Instituição & $\begin{array}{l}\text { Atuação } \\
\text { (Cargo 1) }\end{array}$ & $\begin{array}{l}\text { Atuação } \\
\text { (Cargo 2) }\end{array}$ & $\begin{array}{l}\text { Tempo de } \\
\text { magistério }\end{array}$ & $\begin{array}{l}\text { Formação } \\
\text { Acadêmica }\end{array}$ \\
\hline $\begin{array}{l}\text { Abigail } \\
\text { Quagraine- } \\
\text { Grupo étnico } \\
\text { AshantiAkan }\end{array}$ & $\begin{array}{l}\text { Fountain Head Cristian } \\
\text { School }\end{array}$ & $\begin{array}{l}\text { Sala de aula } \\
1 \text { turno }\end{array}$ & $\begin{array}{l}\text { Auxiliar de } \\
\text { Secretaria }\end{array}$ & 05 anos & Pedagogia \\
\hline $\begin{array}{lr}\text { Awanab } & \text { Daniel } \\
\text { Kofi }- & \text { Grupo } \\
\text { étnico - Builsa } & \\
\end{array}$ & $\begin{array}{l}\text { Tutuka M/A Junior High } \\
\text { School }\end{array}$ & $\begin{array}{l}\text { Sala de aula } \\
1 \text { turno }\end{array}$ & $\begin{array}{l}\text { Agricultura } \\
\text { familiar }\end{array}$ & 11 anos & $\begin{array}{l}\text { Desinebásico } \\
\text { Tecnologia }\end{array}$ \\
\hline $\begin{array}{l}\text { Catherine Mariah } \\
\text { Mensah- Grupo } \\
\text { étnico Akan } \\
\text { Tribo Ashanti }\end{array}$ & $\begin{array}{l}\text { Associação de Mineiros } \\
\text { da Anglo Golden }\end{array}$ & $\begin{array}{l}\text { Alfabetização } \\
\text { de Mulheres } \\
\text { adultas }\end{array}$ & $\begin{array}{l}\text { Fabrica } \\
\text { pimenta em } \\
\text { conserva. }\end{array}$ & 20 anos & Pedagogia \\
\hline $\begin{array}{l}\text { Mantani } \\
\text { Salifu - } \\
\text { Grupo étnico - } \\
\text { Guanj } \\
\text { Gonja }\end{array}$ & $\begin{array}{l}\text { Jimiso Methodist Junior } \\
\text { High School - Obuasi }\end{array}$ & $\begin{array}{l}\text { Informação } \\
\text { e } \\
\text { Educação } \\
\text { Tecnológica } \\
- \\
\text { Ensino } \\
\text { Médio } \\
\end{array}$ & $\begin{array}{l}\text { Trabalha } \\
\text { como } \\
\text { costureiro } \\
\text { em uma } \\
\text { fábrica de } \\
\text { roupas. }\end{array}$ & 04 anos & $\begin{array}{l}\text { Pedagogia } \\
\text { Básica }{ }^{8}\end{array}$ \\
\hline $\begin{array}{lr}\text { Mavis } & \text { Kped - } \\
\text { Grupo } & \text { étnico } \\
\text { Ewe } & \\
\end{array}$ & $\begin{array}{l}\text { Jimiso Methodist Junior } \\
\text { High School - Obuasi }\end{array}$ & $\begin{array}{l}\text { Sala de Aula } \\
1 \text { turno }\end{array}$ & Estuda & 03 Anos & $\begin{array}{l}\text { Educação } \\
\text { Infantil }\end{array}$ \\
\hline $\begin{array}{ll}\text { Obed Boateng - } \\
\text { Grupo étnico } \\
\text { Akan - Tribo } \\
\text { Ashanti }\end{array}$ & $\begin{array}{l}\text { JimisoMethodist Basic } \\
\text { School }\end{array}$ & $\begin{array}{l}\text { Escola } \\
\text { Língua } \\
\text { Inglesa }\end{array}$ & $\begin{array}{l}\text { Agricultura } \\
\text { familiar - } \\
\text { cacau }\end{array}$ & 12 Anos & $\begin{array}{l}\text { Licenciatura } \\
\text { Língua } \\
\text { Inglesa }\end{array}$ \\
\hline
\end{tabular}

Fonte: Elaborado pelas autoras

$\mathrm{Na}$ escola, todos (as) os (as) professores (as) de Obuasi trabalham com os alunos da educação básica, do primeiro até o nono ano, o que corresponde ao ensino fundamental I e II do sistema de educação brasileiro. Durante o período da manhã os professores dão aulas teóricas, no período da tarde são ministradas as aulas práticas de culinária, agricultura e informática, e às sextas-feiras eles são responsáveis pelas atividades esportivas e de Educação Física. Assim, os professores de Obuasi transitam por diversas séries e saberes teóricos, práticos e tecnológicos, possuindo competências múltiplas, dentre elas a de educar para o mundo do trabalho, que é uma das propostas das escolas locais.

A função de professor (a) em Ghana, tal qual no Brasil, é considerada de menor prestígio social e conseqüentemente a perspectiva de remuneração também é baixa, quando

7Builsa - Uma das nove cidades da região Norte de Ghana - a origem da cidade é o povo denominado Builsa, cuja língua de origem era Buli da qual seus descendentes muito se orgulham.

8Akrokerri College of Education (Colégio de Educação) - Colégio fundado em 1962 que a partir de 2004 passou a certificar professores (as) para a Educação Básica. 
comparada às outras profissões que exigem o curso superior. A remuneração dos (as) professores (as) em Obuasi é bem abaixo do valor dos cargos considerados de maior prestígio social, como médicos, dentista, engenheiros, advogados, dentre outros. Há uma organização sindical da educação em Obuasi, que realiza reuniões periódicas, atos de protesto, reivindicando melhores salários e condições de trabalho.

A legislação brasileira permite ao (à) professor (a) possuir dois cargos como docente, mas em Obuasi o (a) professor(a) não tem possibilidade de lecionar em dois turnos devido ao cumprimento de uma carga horária integral, isto é, diariamente das 08:00 às 16:00 horas. Sendo assim, os (as) docentes só podem exercer outra atividade à noite, após o expediente escolar.

As diretrizes para o ensino de História no país orientam que desde a mais tenra idade a criança deve conhecer a história da nação, antes mesmo que faça uso do livro de História, que em Obuasi é utilizado a partir do $4^{\circ}$ ano do ensino fundamental I, quando é abordado o processo de emancipação da África, no qual o primeiro presidente de Ghana, Kwame Nkrumah, foi um dos organizadores do movimento ${ }^{9}$ de libertação dos países africanos na década de 1950. Ghana ainda era uma das colônias britânica na África, quando os líderes ghanenses começaram a lutar pela independência.

Os (as) professores(as) de Obuasi revelaram detalhes sobre suas atividades em sala de aula e sobre a história da África e dos povos africanos, conforme consta nos seguintes depoimentos:

Há livros de História da África, porém, na escola nós iniciamos contando para os nossos alunos sobre a independência de Ghana, que ocorreu em 06 de março de 1957. Desde a primeira classe [ $1^{\circ}$ ano do ensino Fundamental] eles [alunos] são ensinados sobre o nosso líder Kwame Nkrumah, primeiro presidente do país, criador do lema "é melhor ser independente para governar sozinho, bem ou mal, do que ser governado pelos outros". Essas aulas são dadas ao longo dos trimestres sempre com os alunos assentados em roda, participando e tendo suas dúvidas esclarecidas. (Professor Obed Boateng)

Uma professora completa:

A capital do Reino Ashanti, Kumazi, fica a $50 \mathrm{~km}$ de Obuasi, conhecemos bem a história do Reino. Para formação da identidade do aluno e do seu pertencimento em relação à raça [e à] cor, é importante que o estudante conheça sua história de origem, e na escola [é contada] a história de sua cidade, do seu país, as conquistas da nação. Começamos a ensinar pela

9 Na década de 1950 diversos países africanos conquistaram a independência, livrando-se de seus colonizadores europeus, por meio do "Movimento de libertação nacional". 
independência porque foi um marco no país, a nação passou a ser organizada por uma pessoa de Ghana, estamos demonstrando a força da nação. (Professora Abigail)

Os depoimentos desses professores demonstram uma prática didático-pedagógica a partir do conhecimento da história de independência do país, o autoconhecimento de suas origens, o pertencimento nacional. De acordo com os (as) professores(as), no currículo escolar a história de Ghana inicia-se a partir da independência. Os alunos são informados sobre o processo de descolonização do país em rodas de conversa, desde a primeira classe, que corresponde à $1^{\text {a }}$ série do ensino fundamental I no Brasil.

\section{Aspectos Metodológicos}

As sociedades modernas vivem um momento de revolução tecnológica e as pesquisas em educação também estão sendo influenciadas por essas mudanças. Essa nova realidade viabilizou a realização desta pesquisa entre dois continentes ainda que professores de Ghana tivessem estado presentes no Brasil por apenas 15 dias, mais precisamente em Sabará, MG, cidade que consideram irmã. Depois da visita técnico-pedagógica e troca de experiência com os professores do município de Sabará em 2018, os professores do distrito de Obuasi participaram do diálogo e da troca de experiência através das postagens diárias de vídeos e fotos. No decorrer da troca de mensagens percebeu-se o uso constante de emojis ${ }^{10}$, como forma de interação e descontração entre os (as) professores (as) participantes, os quais fizeram uso dos mesmos em sintonia e sincronia, representando diversas situações como: as emoções humanas, a disponibilidade de tempo, a alimentação e a disponibilidade de tempo de cada pessoa, dentre outras situações do cotidiano e especificidades tribais.

O uso dos emojis proporcionou um espaço descontraído, demonstrando um pouco a personalidade e a espontaneidade dos participantes. Observou-se que, apesar de ser um espaço virtual, a interação foi humanizada por meio da demonstração de felicidade, preocupações, felicitações, aprovação, incentivo, dentre outras. Os participantes aprimoraram seus conhecimentos das técnicas de comunicação à distância ao longo da pesquisa, fazendo uso das conversas via Skype, ferramentas não convencionais no cotidiano dos professores

10 Emoji é uma palavra derivada da junção dos seguintes termos em japonês: e + moji. Com origem no Japão, os emojis são ideogramas e smileys usados em mensagens eletrônicas e páginas da web, Exemplos de emojis:

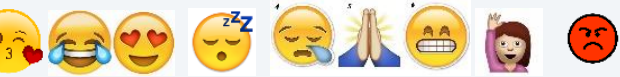


pesquisados e tiveram uma formação em serviço sobre a utilização dessas ferramentas. A participação na pesquisa exigia que o (a) professor (a) fizesse uso de diversos recursos digitais, desafio que foi aceito e desempenhado pelos docentes. Os equipamentos utilizados foram: tabletes, computadores e smartphones fora e dentro de laboratórios de informática.

A interação online é eqüidistante de uma interação real, quando se trata de pesquisa, no entanto, coube às pesquisadoras dispor de criatividade para obter a interlocução necessária. Outro aspecto da pesquisa etnográfica virtual é não estar fisicamente na pesquisa de campo. Para compensar a não presença estivemos em contato com os sujeitos da pesquisa por mais tempo. Além do período específico para coleta de dados.

Os participantes expuseram-se naturalmente no espaço virtual e compartilharam imagens de sua sala de aula, planejamento escolar, horário de recreio, espaços de lazer e até fotos de familiares. Os estudos etnográficos virtuais exigem critérios de observação e procedimentos de coleta de dados específicos para que a etnografia não seja tomada como "sinônimo supostamente legítimo para uma mera observação e monitoramento" (AMARAL, 2010, p.129).

\section{Os grupos étnicos e os grupos tribais em Ghana}

Obuasi, cidade situada no Sul de Ghana, tem cerca de 120 mil habitantes, fica a 225 km da capital do país Accra e a 54 km de Kumazi, capital do Império Ashanti. Dividida em 10 regiões e considerada uma das mais desenvolvidas do país, a cidade cresceu após a descoberta de um depósito de ouro no século XIX (um dos mais ricos do mundo). O município, que tem na mineração a sua principal fonte de renda, abriga diversos grupos étnicos, dentre eles, os Ashanti, Gonja, Ba e Builsa. A língua oficial local é o inglês, porém, as línguas nativas Twi e Fante são faladas pela maioria da população (IMPÉRIO, 2016). A população total de Ghana é de aproximadamente 31 milhões de habitantes.

O Reino Ashanti é um reino pré-colonial criado pelos Akans, maior grupo étnico de Ghana (48\% da população local), e sediado na cidade de Kumasi ${ }^{11}$. A língua Twi é a língua nativa mais falada em Ghana e em Obuasi é a língua de $40 \%$ da população, tornando a escola bilíngue, pois as crianças aprendem esse idioma e o inglês, concomitantemente.

Atualmente, a monarquia é a forma de governo do estado subnacional constitucionalmente protegido dentro da República de Ghana. A sucessão do rei e da rainha

11 Kumasi está localizada a $54 \mathrm{~km}$ de Obuasi, distante $250 \mathrm{~km}$ da capital Accra. 
não é hereditária, pois segue o critério de seleção entre as pessoas consideradas mais sábias e preparadas do reino, não necessariamente casados. A continuidade desse reinado é muito importante para os ganenses, pois significa que existem pessoas capazes de liderar o povo a partir das tradições e não da colonização, uma característica considerada símbolo de originalidade.

O Reino dos Ashanti possui palácio, súditos, guarda real, muitos terrenos e muita riqueza mineral. Além disso, há um exército exclusivo do Reino Ashanti, não integrado às forças armadas de Ghana, mas recrutado e mantido pelo rei Ashanti. O ouro é um dos símbolos de riqueza, muito presente nos adereços reais. As habilidades dos ganenses com o ouro são evidenciadas na riqueza de detalhes dos adereços reais e objetos do palácio.

O tecido de nome Kente, criado há vários séculos pelo grupo Akan, mantém a tradição de ser feito pelo núcleo familiar. Produzido no Reino Ashanti, na cidade de Kumasi, localizada na região metropolitana, o tecido consiste em fios de algodão tecidos manualmente em um tear na vertical, produzindo faixas de aproximadamente 20 centímetros de largura por um metro e meio de comprimento, depois estas faixas são costuradas entre si, formando um tecido maior e único (TRIP DOWN MEMORY LANE, 2012).

Um produto utilizado na indústria de cosméticos (óleo, loção e hidratante) e bastante consumido no Brasil é a manteiga de karité ${ }^{12}$. Na África, a manteiga de Karité não é utilizada apenas na indústria de cosméticos, mas também na culinária. No Brasil, a manteiga de Karité é utilizada no preparo das comidas dos Orixás, em especial na comida de Oxalá, nas religiões de matriz Africana como o Candomblé. Em Ghana, o preparo da manteiga de Karité como hidratante, produtos de embelezamento e ou manteiga para culinária é feito manualmente por mulheres. Há uma produção industrializada, no entanto, a produção artesanal mantém a empregabilidade de milhares de mulheres. As mulheres atuam no plantio, colheita, produção e distribuição da mercadoria.

Em Ghana existem mais de 100 grupos étnicos ${ }^{13}$ e tribais ${ }^{14}$ atualmente, porém, a convivência é tolerante, sem histórico de guerra civil, por isso, o país continua como um dos países mais pacíficos de toda a África. Conforme a figura 2 demonstra, o grupo Akan é o grupo ético dominante pois é composto por $49 \%$ da população local. Os demais grupos de

12Manteiga de karité: banha de ori, extraída do fruto de uma árvore exclusivamente africana de nome Karité. 13 Os grupos étnicos possuem semelhanças físicas, mas podem apresentar variedade de línguas; as línguas falantes são variadas, cada grupo possui sua língua de origem não tendo uma língua nativa comum a todos os grupos, não está restrito a um único grupo.

14 As tribos são grupos de pessoas falantes da mesma língua e que possuem os mesmos hábitos, tradições e vestimentas. 
maior expressividade são: Mole, Dagbane e Ewe. Cada grupo étnico mora em tribos ou bairros específicos, definidos pelos professores como vilas15, e possuem seus mercados individuais, escolas, espaço de lazer e quando migram à região da grande Accra16, recriam também seus espaços tribais. Essa migração dentro do próprio país se dá em busca de oportunidades de trabalho e melhores condições de vida. As tribos ocupam espaços, cada vila abriga uma etnia específica, algumas vilas abrigam povos de mais de uma etnia, porém essas são exceção ao modelo de ocupação do solo ganense. Os grupos tribais possuem ofícios que são parte da história de cada uma delas, há grupos étnicos especialistas em caça, mineração, agricultura, pastoreio, tecelagem e criação de aves (são meios de subsistência preservados pelas etnias).

\section{Figura 1 - Distribuição das etnias em Ghana}

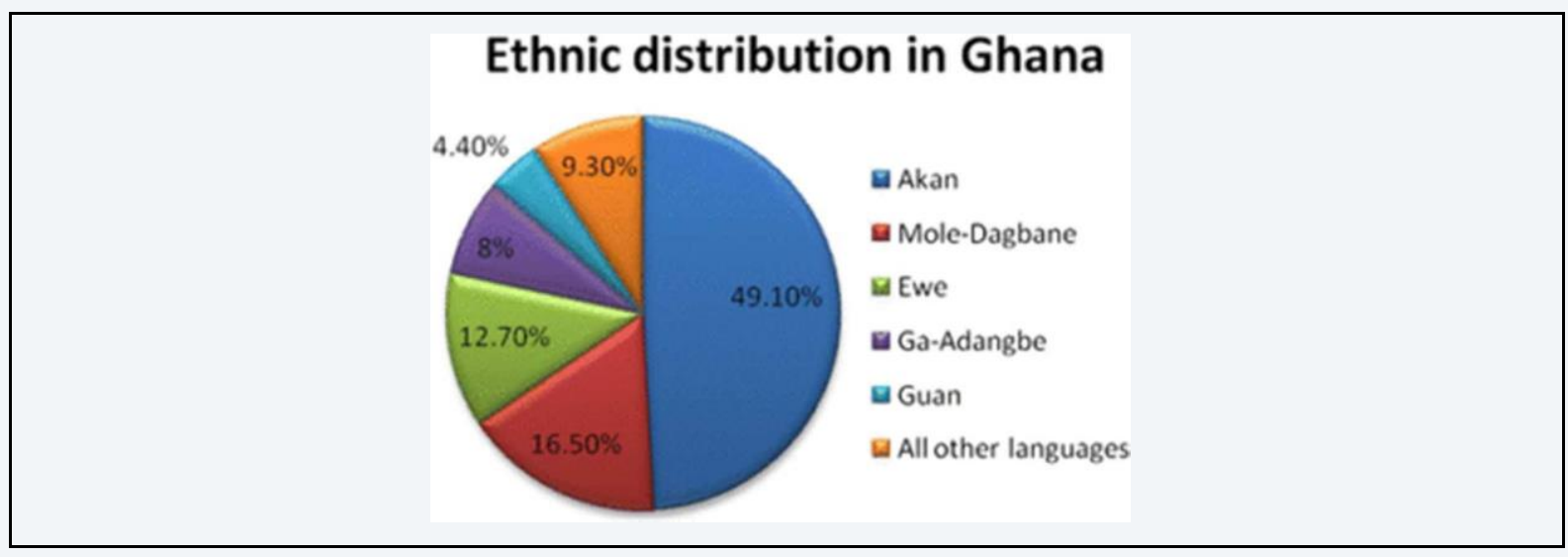

Fonte: Media Objects (2016).

Ghana tem, talvez, o melhor sistema de governo democrático da África na atualidade, em relação aos diversos grupos étnicos, é considerada uma das nações mais bem-sucedidas culturalmente e mantém o orgulho tribal, étnico e nacional. O presidente do país e os demais cargos políticos não são escolhidos apenas por pessoas que pertencem ao grupo étnico Akan, mas por pessoas dos diversos grupos étnicos que compõem o país. O ex-presidente de Ghana, John Mahama, que governou de 24 de julho de 2012 a 06 de janeiro de 2017, não era membro do grupo étnico Ashanti-Akan, pertencia ao grupo étnico Gonja e foi eleito democraticamente, demonstrando que o fato de não pertencer ao maior grupo étnico de

15 Vilas no contexto de Obuasi é referente a um bairro no Brasil. Há algumas vilas na periferia da cidade que possuem em média quatrocentos moradores, mas pertencem ao município de Obuasi, não constituem novos municípios.

16 Accra - Capital de Ghana - região da grande Accra é a região metropolitana de Accra. 
Ghana, não foi empecilho para vencer as eleições. Nas eleições de dezembro de 2017, foi eleito Nana Akufo-Addo, proveniente da região oriental, do grupo Akropong-Akuapem, um grupo menor, o que segundo os participantes da pesquisa, demonstrara a maturidade dos eleitores ao escolher um governante por sua competência política.

Os professores de Obuasi acreditam que esse orgulho tribal e o pertencimento que defendem, não têm prejudicado as decisões políticas, ao contrário, tem contribuído para que a eleição seja mais criteriosa, fazendo jus ao lema nacional: "É melhor ser independente para governar sozinho, bem ou mal, do que ser governado pelos outros". O lema foi um dos propulsores da independência do país em 1957 e foi apropriado pelos ghanenses, que analisam a vida dos candidatos para votarem em alguém que possa honrá-los.

O relato de um professor sobre o comportamento dos membros de outras tribos possibilita melhor entendimento do dia a dia dos ganenses.

Os Akan se sentem superiores aos demais povos, se acham mais inteligentes, dotados fisicamente de força, desenvolvidos intelectualmente, e se comportam como detentores do saber em detrimento do atraso dos outros. Para os Akan os demais grupos são considerados bobos, muito atrasados, sem acesso à tecnologia, etc. (Professor Hudu, 2016).

Esse depoimento é de um professor de uma das tribos da Região Norte do país, considerada menos desenvolvida por manter a tradição de agricultura familiar e pastoreio de rebanhos. Os povos dessa região buscam por educação, qualificação e saúde nas regiões mais centrais de Ghana, pois o número de escolas é insuficiente para o quantitativo populacional, portanto, não há vagas para todos, como afirmam os (as) professores (as) participantes da pesquisa. A Região Norte detém o maior índice de analfabetismo, desemprego, falta de saneamento básico e serviços públicos, o que demonstra diferenças culturais e desigualdade econômico-social. Há no país um fluxo de migração para as regiões centrais em busca de melhor qualidade de vida, qualificação profissional e formação educacional. No entanto, devido à falta de formação e qualificação profissional, os cargos ocupados pelos migrantes dessa região são sempre de faxineiros, repositores em supermercados, serviços domésticos e outras profissões de menor remuneração e prestígio social, além de trabalhos informais como vendedores autônomos ou criadores de animais para comercialização.

Segue alguns depoimentos dos professores sobre a situação social e educacional do pais, de um modo geral: 
Em Ghana o governo não está preocupado com as condições de trabalho do professor em sala, todas as escolas públicas são sucateadas, pisos ruins, quadros negros velhos, gastos, não temos armários para guardar materiais pessoais. (Professor Obed)

[...] o investimento é do governo para a escola, que foram construídas e depois não receberam verbas de manutenção, então com o passar dos anos, todas as escolas vão ficando sucateadas. (Professor Hudu)

Todo candidato promete melhorar a educação no país, agora que estamos em campanha presidencial ${ }^{17}$ é uma das promessas feitas pelos candidatos. Todos prometem melhorar a educação; só promessas, nunca cumprem.(Professora Abigail)

Eu leciono informática e há 06 computadores para uma sala de 70 alunos, é muito difícil trabalhar, faço grupos para cada computador, o aprendizado fica comprometido. Eu leciono para sala com 80 a 120 alunos, são 6 computadores no laboratório, é muito difícil dar aula, preciso colocar os alunos em grupo, compromete o aprendizado e as condições de trabalhado para o professor são ruins. (Professor Hudu)

\section{Um filho ilustre de Ghana: Kofi Annan, secretário geral da ONU}

Kofi Atta Annan (1938*-2018+), do distrito de Kofandrus de Kumasi, é considerado um fiho ilustre de Ghana e cidadão honorário. Entre janeiro de 1997 e dezembro de 2006, Kofi Annan atuou como secretário-geral da Organização das Nações Unidas (ONU), tendo recebido o Prêmio Nobel da Paz em 2001. Kofi Annan nasceu no distrito de Kofandros de Kumasi, a qual era, na época, colônia britânica da Costa do Ouro. Ele foi irmão gêmeo, o que dá uma posição de respeito na cultura de Ghana. Sua irmã gêmea, Efua Atta, que morreu em 1991, compartilhava seu nome do meio Atta, que em fanti e akan significa gêmeo. Na tradição antroponímica de Akan, algumas crianças são nomeadas de acordo com o dia da semana em que nasceram, e/ou em relação a quantas crianças as precederam. Kofi em Akan é o nome que corresponde à sexta-feira.

\section{As tradições culturais tribais em Ghana}

As tradições culturais tribais em Ghana são muito diversificadas, alguns grupos étnicos expressam sua identidade tribal por meio das marcas faciais, utilizadas para identificação, embelezamento, tratamento médico tradicional e proteção espiritual. As

17A eleição para presidente em Ghana foi realizada no dia 07 de dezembro de 2016, quando foi eleito Nana Akufo-Addo, candidato da oposição e os(as) professores(as) estavam bem atentos(as) às propostas dos candidatos ao cargo. 
imagens das figuras 15 e 16 mostram pessoas de etnias diferentes e marcas faciais específicas, o traçado identifica o grupo étnico. Alguns alunos possuem marcas faciais, mas, dentro da escola, há respeito e um tratamento amigável, amistoso, de acordo com os professores não há discriminação. As marcas tribais contribuem para identificação do grupo étnico.

\section{Figura 2 - Mulher com marcas tribais}

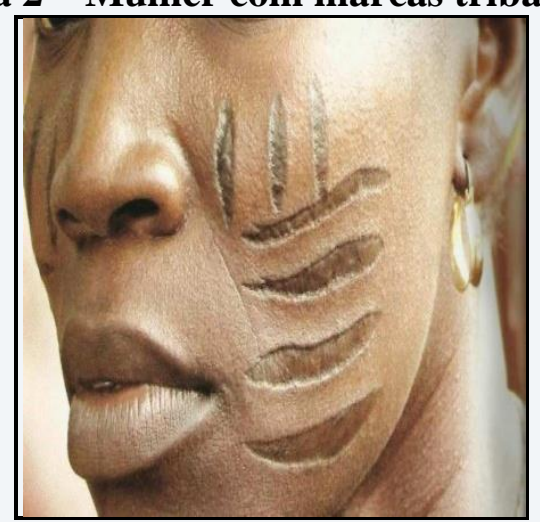

Fonte:OMG Voice, 2016.

\section{Figura 3 - Homem com marcas tribais}

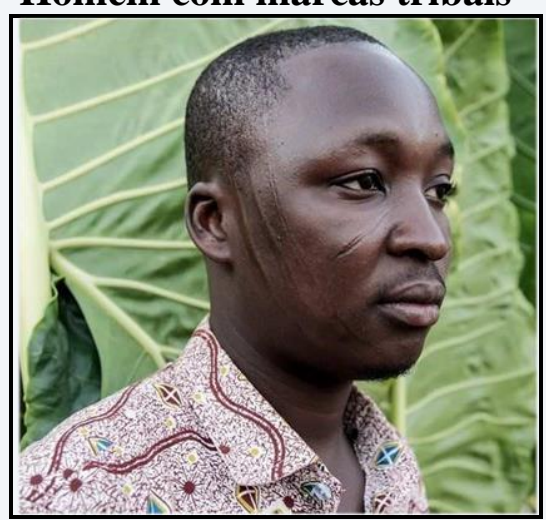

Fonte:OMG Voice, 2016.

A origem da prática de marcar a face é desconhecida, mas, a tradição tem passado de geração em geração. Dentre as tribos que possuem essa tradição estão: Gonjas, Naumbas, Dagombas, Frafras e Mamprusis. As marcas faciais são feitas na criança recém-nascida ou até os cinco anos de idade, como sinal de lealdade dos pais às tradições dos ancestrais. Em Ghana, a prática não é proibida por lei, no entanto, o país sofre pressão de grupos humanitários externos, que a definem como agressão ao indivíduo, mutilação e evidenciam o risco de morte para a criança, que marcada com poucos dias ou meses de vida, está mais suscetível à infecção. Os grupos étnicos decidiram manter a prática, por entenderem que é uma herança ancestral, há centenas de anos se identificam assim e intentam continuar. Os membros dos grupos que fazem as marcas faciais nos filhos se sentem orgulhosos por manterem a tradição e os adultos que as possuem se sentem protegidos espiritualmente.

Os grupos étnicos que residem mais próximos à Região Metropolitana de Accra já estão deixando essa tradição, não marcando recém-nascidos, por entenderem que isso não interferirá na formação étnica da criança. A mudança de comportamento gera incerteza quanto ao futuro das marcas faciais, pois a globalização, os avanços tecnológicos e o acesso às outras culturas também contribuem para que haja mudança nas práticas culturais em geral.

O tribalismo foi definido ao longo desta reflexão como um dos fatores de perpetuação das origens e dos valores das tribos, ou seja, uma contribuição de afirmação das identidades étnicas da população de Ghana, das culturas e das línguas, uma relação de alteridade com a 
tribo. As sociedades tribais com princípios de auto organização são independentes, pertencer a um grupo étnico é fundamental para as sociedades africanas.

O pertencimento étnico está intrínseco em cada ghanense, faz parte da história de cada um, e é notório o desejo de perpetuação dessas práticas. De acordo com o professor Obed Boateng, o nome de cada indivíduo determina sua tribo, profissão, valores, crenças, religião, o dia de nascimento, a região do país, a língua de origem, demonstrando a preciosidade que é manter as tradições. A educação escolar em Obuasi tem esse desafio, cumprir com o seu objetivo de educar, sem inferir na essência das culturas tribais.

O país não tem histórico de conflitos entre os grupos étnicos como dito anteriormente, porém, a interação entre as tribos ainda não é uma realidade, se pensado à partir do sistema educacional. O diálogo entre os grupos tribais não é proposto como uma unidade dos valores, língua e costumes, mas sim como uma conduta de auto afirmação enquanto nação, em busca de melhores condições socioeconômicas para a população. A busca pelo bem coletivo, não reivindica ações que privilegiem tribos individuais, mas um estado nação, para (CARDOSO DE OLIVEIRA, 1968, p. 209-210) não se trata de uma aculturação, tornar-se igual ao outro, perder-se de seu próprio ser, mas sim de uma convivência cujo propósito é de ajuda mútua entre os grupos.

Os avanços tecnológicos, as mudanças sociais e econômicas contribuem para que as interações entre os povos possam ocorrer. Os grupos tribais possuem acesso à internet, aos aplicativos de mensagens, dentre outras formas de comunicação. A escola está empenhada em promover esta aproximação entre as tribos.

\section{Tribalismo cultural e espaços de aprendizagem}

O pertencimento tribal, ou tribalismo cultural, constitui um conjunto de saberes recebidos desde o nascimento em um reduto tribal através da tradição oral, com o objetivo de formar integralmente a pessoa humana. A dedicação aos estudos, a disciplina em sala, as práticas agrícolas e laborais e os demais trabalhos manuais ajudam a tecer a essência dos povos de Obuasi no espaço de aprendizado. O respeito ao professor, aos mais velhos em geral, faz parte da cultura tribal ghanense. A exaltação de suas belezas físicas, conhecimento intelectual, a religião, a língua nativa, a autoconfiança para atuar no mundo e o respeito à natureza é parte integrante de cada grupo étnico. Mas, o que significa exatamente isso? Como 
o aprendizado tribal pode ser válido na vida dos adultos nos tempos atuais e nos lugares onde se encontram?

A cultura tribal ficou explicita nas postagens dos professores (as) de Obuasi, posto que frequentemente demonstravam peculiaridades de seus grupos tribais: as datas comemorativas, os rituais de passagens para puberdade, os nomes tribais de acordo com o dia de nascimento da criança, tipos de alimentação, ofícios laborais e postura profissional. Um desafio importante para os participantes e os demais membros de suas tribos era como articular a atividade educativa com uma formação humana integral a partir do pertencimento tribal. O conceito de tribo em Ghana serve para resignificar. Há um sentimento de pertencimento e de alteridade. No Brasil o termo tem sido utilizado da mesma forma por parte, principalmente dos jovens, ao se referirem a um grupo urbano como: "minha tribo". Os jovens não expressam repulsa, ao contrário se auto afirmam. Os jovens brasileiros procuram pertencer a algum grupo, querem ser parte da "tribo", estarem em evidencia, e se fortalecerem.

A revolução tecnológica do século XXI, não desintegrou o tribalismo cultural de Obuasi, apesar da globalização criar padrões universais, como se todas as culturas fossem iguais. Os valores culturais próprios dos povos de Obuasi permanecem. Cunha (1986) preconizara que o tribalismo não seria erradicado, mesmo diante de grandes mudanças globais, afirmando que o chamado tribalismo não desapareceria nas cidades modernas africanas, mas que, ao contrário, ele se exacerbaria, demonstrando que as estruturas organizacionais dos povos tribais podem sobreviver às mudanças sociais. Os valores e vínculos culturais dos grupos étnicos de Ghana são enraizados, as pessoas querem preservar suas particularidades, não há entre o grupo de professores uma visão de desagregação cultural, o que se percebe é o oposto, um empenho em se preservar as culturas nativas.

Tanto a definição de Ribeiro (1977) quanto a afirmação de Cunha (1986), fundamentam o conceito de tribalismo, explicitado pelos professores de Ghana, com relação às suas tribos e ao lugar de formação da identidade de um grupo, que possui relações sociais próprias. No contexto brasileiro, tribalismo, nos remete aos grupos étnicos indígenas e quilombolas. Ribeiro (1977), afirma que o índio, independentemente de sua proximidade e ou inserção em outra cultura, manterá sua formação identitária, ou seja:

Se o índio é cada vez mais cercado de um contexto civilizado ou comercializado, se ele próprio se converte em mão de obra, se ele próprio tem que produzir mercadoria, é claro que ele tem uma integração cada vez maior com a sociedade nacional. Mas esta integração não quebra nele a 
identidade como indígena. Apesar de transformados os costumes, apesar de mudar os modos de se vestir. Apesar de todas essas mudanças ele permanece indígena. (RIBEIRO, 1977, p.39).

No contexto de Obuasi, a integração ao mundo globalizado e o acesso ao conhecimento fora do espaço da tribo, não parece ter comprometido a identidade étnica dos ghanenses, a cultura de cada grupo étnico, foi realçada na postura dos (as) professores (as) participantes da pesquisa ao falarem de si, assim como a integração urbana "não quebra a identidade indígena" a educação escolar "não quebra" a identidade dos povos de Obuasi. O tribalismo cultural é um pertencimento que vai além do espaço de residência, das vestimentas e rotinas estabelecidas.

Não consta no currículo como matéria de História para o ensino fundamental I, a história da África. Eles estão na alfabetização, a história de Ghana é narrada para eles em uma roda de conversa. Eles aprenderão sobre o país e seus símbolos (Professora Catherine Mariah)

O termo tribalismo cultural está sendo definido a partir das informações de pertencimento de cada grupo étnico compartilhado pelos professores de Obuasi como: língua, ensino através da tradição oral, tipos de tecidos, acessórios, adornos para celebrações, danças, músicas, nomes tribais, alimentação e ofício laboral. Nas escolas participantes da pesquisa são encontradas as etnias Ashanti, Gonja, Ga, Ewe e Fante que convivem em uma relação de respeito a sua cultura e a cultura do outro.

Cunha (1986) afirma que: "Na África das lutas de independência e pós-colonial, a etnicidade era vista como um empecilho à constituição de uma nação moderna, e acusava-se o tribalismo de dificultar a construção". Ao invés de sucumbir, no entanto, o tribalismo se exacerbou, pois, os grupos se mantiveram mais fiéis às suas origens e tradições. Os grupos étnicos de Ghana sobreviveram ao período colonial, à espoliação de suas culturas, bens, ofícios e territórios. Como citado por Ribeiro (1970), “o mundo de um povo é ele próprio”, os povos se reconstroem desde a independência do país, a partir dos relacionamentos entre os membros de cada etnia. A cultura foi mantida a partir da tradição oral, da prática dos estilos tribais de vida e da importância funcional da tribo. A educação das crianças nas instituições tribais também é um fator relevante para continuidade da vida e das tradições, fazendo com que ao ser inserida no processo de escolarização, a criança tenha consigo o seu pertencimento grupal.

A história dos povos africanos é aprendida na tribo. Uma criança de 07 anos já aprendeu com os anciãos de sua tribo sobre seus ancestrais, conquistas de 
seus povos, ocupação daquele espaço de moradia e qual é o ofício ${ }^{18}$ do grupo (Professor Mavis Kped)

\section{Tribalismo cultural no espaço escolar}

A escola não ensina sobre os povos e reinos, porque só em Ghana são mais de 10 tribos e entendemos que essa função é da tribo, o aluno precisa aprender com sua comunidade, com os anciãos, é parte da nossa tradição (Professora Abigail)

De acordo com os relatos dos professores participantes da pesquisa os alunos ao iniciarem os estudos escolares, já conhecem toda a história de suas famílias que foram narradas pelos chefes tribais. Há uma formação que enaltece os heróis locais, cada tribo possui seus heróis, heroínas e feitos dos quais se orgulham. A comunidade local e escolar sabe que é a educação que imprime as características específicas que fazem de uma criança um membro da sociedade. A disciplina é apreendida no espaço tribal, de acordo com os professores não há situações de indisciplinas e desrespeito ao corpo docente, uma vez que o aluno recebe essa formação no espaço da tribo para honrar e respeitar os mais velhos. A importância da hierarquia é aprendida pelas crianças na prática, o respeito aos chefes, aos mais velhos, aos pais, aos professores não se limitando a parentes especificamente, mas a posição ou cargo ocupado na tribo e na sociedade.

Na contemporaneidade, o tribalismo cultural vivenciado pelos (as) professores (as) de Obuasi, está presente no contexto escolar, desafiando os (as) docentes a construírem uma educação capaz de lidar com as especificidades tribais. Até o ano de 2016, em Obuasi, as escolas não trabalhavam a questão do tribalismo como prática didático pedagógica, porém ao término do ano letivo, em julho de $2016^{19}$, e início de 2017 alguns diretores solicitaram que essa questão fosse introduzida nas práticas pedagógicas para promoção de uma educação mais coesa no município.

As atividades referentes ao tribalismo cultural no espaço escolar não são regulamentadas por lei, não há políticas públicas, ou formação docente que oriente os professores como viabilizar práticas pedagógicas para promover as "relações educacionais tribais" ${ }^{20}$. Os (as) professores (as) que participaram da pesquisa buscam diretrizes que

18 Cada grupo étnico tem um ofício principal como: confecção do Kent, plantação de cacau, plantação de milho, extração mineral, confecção de roupas, dentre outros.

$19 \mathrm{O}$ ano letivo em Obuasi inicia em setembro e finda em julho do ano seguinte, portanto o $1^{\circ}$ semestre de 2017 iniciou-se em setembro de 2016.

20 Relações educacionais tribais: termo criado para se referir a uma educação que promova um diálogo entre as tribos para uma educação humanitária. 
valorizem a origem de cada grupo e dialoguem com os demais grupos, sem evidenciarem alguns grupos em detrimento dos demais. A convivência amigável entre os alunos se limita a não se provocarem e ou exaltarem as diferenças, se respeitam, mas não estabelecem um ambiente de solidariedade entre etnias diferentes, no qual as pessoas conversam entre si, compartilham experiências, se ajudam no que for necessário. Ao iniciarem um trabalho para as relações educacionais tribais, não significa para os professores de Obuasi uma educação padronizada, formatada, globalizada, mas sim uma educação que contemple todos os grupos étnicos, valorizando as especificidades de cada um deles, possibilitando um diálogo para além da sala de aula, o que não ocorre no momento. Os estudantes só conversam com pessoas de seus grupos tribais, após o término da classe e ou durante os intervalos, os professores são os mediadores das conversas e atividades em classe.

Desenvolver um trabalho educativo para as relações educacionais tribais ficou a cargo dos (as) professores (as) de Língua Inglesa e Twi21, por determinação do diretor, que iniciaram o diálogo com os estudantes. Há divergências entre os (as) professores (as) quanto à realização de atividades escolares que abordem as questões tribais, culturalmente o tema não é de responsabilidade da escola, há outros espaços educativos, dentre eles o próprio espaço tribal. Há entre os professores alguns pontos convergentes com relação ao tribalismo e a educação escolar, dentre eles o estudo de suas línguas nativas. A escola em Obuasi é bilíngue, os alunos são alfabetizados simultaneamente em Twi, uma das línguas da região Ashanti, e em Inglês que é a língua oficial do país. Ambas as línguas estão presentes nos livros didáticos e nas atividades diárias dos (as) docentes, como pode ser verificado na Figura 1.

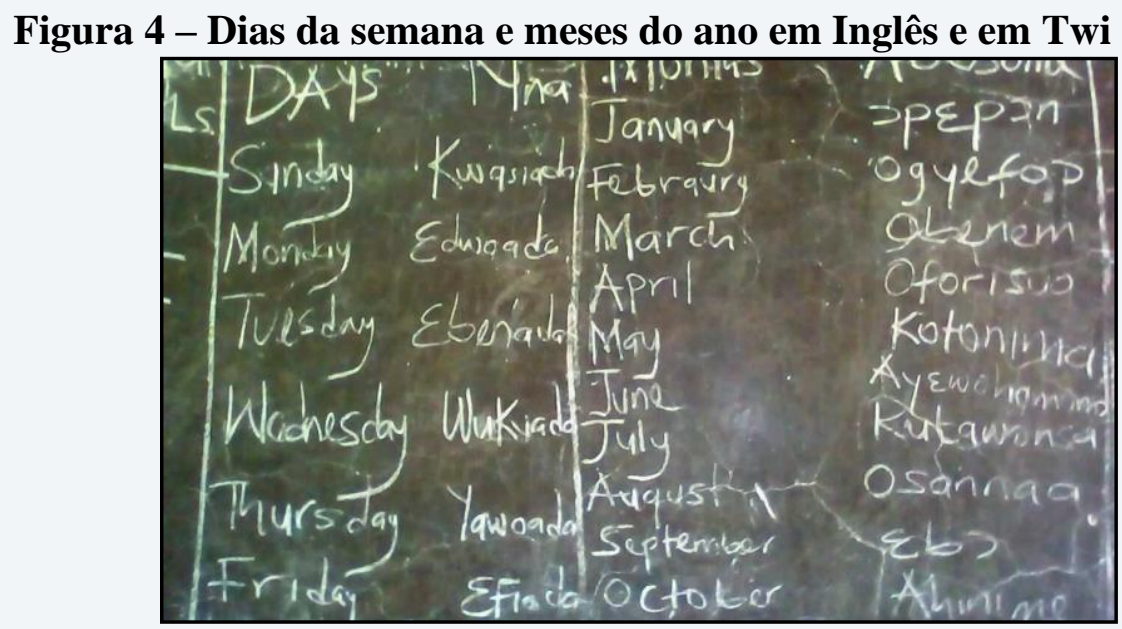

21 Twi - Língua do grupo Ashanti que é o maior grupo étnico da região Ashanti, portanto, o idioma ensinado na escola é do grupo majoritário. 
A escolarização em Twi, língua tribal, é considerada fundamental para os (as) participantes da pesquisa, como preservação da identidade local. Segundo eles (as), a educação não deve ser exclusivamente na língua do colonizador, quando se referem ao Inglês, pois o país, já possuía diversas línguas locais quando se tornou colônia da Inglaterra. A diversidade de línguas é um dos desafios para a interação social escolar, como afirma um professor:

Não é só o idioma que dificulta a convivência com outros grupos na escola, o tipo de comida, o modelo de roupa, a música que cantamos e tocamos e o ofício de cada grupo. Na nossa região falamos Twi e Fante como línguas locais, quem fala esses dois idiomas consegue se comunicar bem com praticamente toda Região Ashanti. (Professor Awanabi Daniel)

Os (as) professores (as) participantes ressaltam a importância de se conhecer as línguas locais para uma interação no espaço da sala de aula, pois a diversidade linguística, no espaço escolar, é um dos desafios na relação ensino-aprendizagem. Professores e alunos falam em média três idiomas: o idioma de origem22, o inglês, o Twi ou Fante.

Os (as) professores (as) afirmam que a regulamentação do uniforme é importante para manutenção da disciplina e da igualdade, mas, que os alunos se conhecem e se identificam pelos seus grupos étnicos independente do uniforme e ou corte de cabelo. Os docentes devem lecionar com roupa social e têm a liberdade de usarem roupas de seus grupos étnicos. A roupa esportiva para docentes somente é permitida na sexta-feira, dia exclusivo de atividades físicas.

Os professores trabalham textos, poemas com a temática de interação tribal, buscando uma sala de aula participativa. Os alunos fazem as interpretações de textos levando-os a reflexões sobre a importância da construção social do pensamento entre os diferentes. A escola promove a interação entre os estudantes através dos times de futebol, compostos por estudantes de diversas etnias, que vivenciam momentos de descontração e cooperação para alcançarem um objetivo comum, que é vencer o jogo, são estratégias para a educação das relações tribais. Durante as partidas de futebol, o (a) professor (a) trabalha questões relacionadas à cooperação entre os grupo. Os times possuem uniforme obrigatório, verificado com rigor, e que funciona como um instrumento de controle para que nenhum dos alunos promova seu grupo étnico através das roupas e acessórios. Os times são treinados para

22 Nas comunidades os professores criaram cursos de alfabetização de adultos, e cada comunidade é alfabetizada na sua língua de origem, após os adultos aprenderem a ler e a escrever em sua língua local, será alfabetizado em Inglês. O ensino do Inglês nas comunidades não é comum, só quando alguém ou um grupo de pessoas demonstra interesse. 
alcançar um objetivo, vencer o jogo, o foco não pode ser negligenciado, não há espaço para questões individuais nesse momento.

Observa-se que a proposta de uma educação para as relações tribais esta iniciando, sem uma definição, ainda, se será estabelecida por via legal e se sim, como. Os trabalhos iniciados pelos professores participantes da pesquisa se limitam às escolas nas quais trabalham, não sendo esse texto referente a todo o sistema educacional de Obuasi, mas uma contribuição referente aos aspectos da manutenção dos elos tribais e suas relações com a escola.

\section{Considerações finais}

As novas tecnologias trazem mudanças e contribuições significativas para pesquisas em educação. No caso em tela, podemos citar o conhecimento da realidade educacional de Obuasi de forma simultânea, já que, diversas postagens eram feitas em tempo real, por meio de hangouts, filmagem das aulas, do recreio, das apresentações, oportunizando uma vivencia virtual. O tribalismo cultural vivenciado pelos (as) professores (as) de Obuasi está presente no contexto escolar, desafiando os (as) docentes a construírem uma educação capaz de lidar com as especificidades tribais. Os (as) professores(as) participantes buscam diretrizes que valorizem a origem de cada grupo e dialoguem com os pertencimentos de todos os estudantes, sem que alguns grupos fiquem em posição de destaque sobre os demais.

Este estudo reconhece uma forma de africanidade em Ghana, por meio do que podemos nomear tribalismo cultural. Esta pesquisa analisou as experiências didáticas e pedagógicas vivenciadas por professores (as) de Obuasi. Estas experiências foram registradas por intermédio das postagens de suas práticas escolares em vídeos, aplicativos de mensagens e fotos, de forma virtual, através de um grupo criado em um aplicativo de mensagens, tendo sido utilizadas tecnologias digitais para a aproximação e diálogo com os (as) professores (as).

O processo de independência da África e a resistência aos colonizadores em Ghana gerou um lema ainda significativo para sua população, que o resgatam sempre que necessário: "É melhor fazer por nós mesmos a deixarem que façam por nós", inspirando um posicionamento nacional. Os (as) professores (as) de Obuasi evidenciaram que o povo não deve se limitar ao papel que lhes é imposto, mas resistir, indagar e modificar a realidade. Nesse sentido, sugerem que o povo brasileiro resista, questione e modifique a situação de preconceito racial e racismo institucional existente. Esses participantes também incentivaram 
os (as) professores (as) negros brasileiros a avançarem na luta pela igualdade racial, evidenciando toda a capacidade intelectual, a criatividade laboral e a beleza da população negra, assim como tem feito as diferentes tribos em Ghana.

Os (as) professores (as) participantes de Obuasi têm buscado uma educação que engrandece a história e valoriza as diferenças tribais, de forma a não reproduzirem desigualdades na escola. Nelson Mandela tem uma frase que diz: "A Educação é a arma mais poderosa para mudar o mundo" e nesta pesquisa encontramos professores (as) que estão contribuindo para que isso se realize com maestria.

Este estudo trouxe elementos para dialogar com as africanidades brasileiras. Apontando que na cosmovisão africana destaca-se:

1. Conhecimento de si mesmo;

2. Valorização das culturas locais;

3. Resgate das origens, sejam étnicas, tribais, raciais ou um somatório;

4. Conhecimento da história nacional e celebração das conquistas sociais.

Conclui-se que há um universo da história africana que se apresenta como possibilidade de novas pesquisas e aprendizados, a partir de questionamentos que surgiram durante este estudo, tais como: a relevância de uma educação bilíngue para as africanidades, as regras impostas exclusivamente ao sexo feminino no espaço escolar, os processos de acesso e permanência dos alunos no espaço escolar e o tribalismo cultural.

O diálogo com Obuasi, Ghana, foi apenas uma contribuição para a imensidão de cultura que é o continente africano. Um dos(as) professores(as) de Obuasi afirmou que a “África é rica em cultura, não apenas em recursos naturais". A cultura foi mantida a partir da tradição oral, da prática dos estilos tribais de vida e da importância funcional da tribo. A educação das crianças nas instituições tribais também é um fator relevante para continuidade da vida e das tradições, fazendo com que ao ser inserida no processo de escolarização, a criança tenha consigo o seu pertencimento grupal.

A história dos povos africanos é aprendida na tribo. Uma criança de 07 anos já aprendeu com os anciãos de sua tribo sobre seus ancestrais, conquistas de seus povos, ocupação daquele espaço de moradia e qual é o ofício do grupo (Professor Mavis Kped)

De acordo com os relatos dos professores, ao iniciarem os estudos escolares os estudantes já conhecem toda a história de suas famílias que foram narradas pelos chefes tribais. Há uma formação que enaltece os heróis locais, cada tribo possui seus heróis, heroínas 
e feitos dos quais se orgulham. Neste contexto, uma intervenção a partir do tribalismo cultural foi uma estratégia importante para elevar este orgulho tribal ao nível das relações interpessoais de solidariedade e diálogo.

Que possamos aprender umas com as outras, pessoas interessadas, professoras (es) e pesquisadoras (es) das africanidades e do tribalismo cultural. Que este estudo possa fortalecer os projetos, reflexões e intervenções promovidas pela Educação das Relações Raciais e as africanidades brasileiras. Uma construção de conhecimento a partir da vivencia compartilhada, que se assemelhe ao processo de tecer uma das tiras do tecido Kente. Nesse entrelaçar, é preciso continuar a tecer até completar o tecido do conhecimento, que segue sempre demandando mais tecituras.

\section{REFERÊNCIAS}

AMARAL, Adriana. Etnografia e pesquisa em cibercultura: limites e insuficiências metodológicas. Revista USP, São Paulo, n.86, p. 122-135, jun./ago. 2010.

CUNHA, Manuela Carneiro da. Antropologia do Brasil: mito, história, etnicidade. São Paulo: Brasiliense; Editora da Universidade de São Paulo, 1986.

OLIVEIRA, Roberto Cardoso de. Urbanização e tribalismo. Rio de Janeiro: Jorge Zahar, 1968.

OMG VOICE. Here Are The Reasons Behind Ghanaian Tribal Marks. 02 de março de 2016. Disponível em: < https://omgvoice.com/lifestyle/ghanaian-tribal-marks>. Acesso em: 27 jul. 2016 Papirus, 1995. (Série Prática Pedagógica)

RIBEIRO, Darcy. As américas e a civilização. Rio de Janeiro: Vozes, 1977.

RIBEIRO, Darcy. Os índios e a civilização. Rio de Janeiro: Civilização Brasileira, 1970.

SILVA, Petronilha Beatriz Gonçalves e. Africanidades brasileiras: esclarecendo significados e definindo procedimentos metodológicos. In: Revista do Professor, 9 (73), p.26-30, jan./mar.2003.Disponívelem:<http://www.revistadoprofessor.com.br/system/biblioteca/materi ais/Africanidade.pdf> Acesso em: 05 de Setembro de 2018.

TRIP DOWN MEMORY LANE. Kente cloth: ghana`sashanti cultural heritage to the world `s fashion civilization. 03 de dezembro de 2012. Disponível em: < https://kwekudeetripdownmemorylane.blogspot.com.br/2012/12/kente-cloth-ghanas-ashanti-cultural.html >. Acesso em:27 jul. 2018. 


\section{SOBRE AS AUTORAS:}

\section{Silvani dos Santos Valentim}

Ph.D em Educação, Temple University, USA; CEFET-MG; PPGET; Dept. de Educação;Programa de Formação Docentes; Coordenadoria de Gênero, Relações ÉtnicoRaciais, Inclusão e Diversidades (CGRID); Pesquisadora do CNPq; Núcleo de Pesquisa e Estudos Afro-Brasileiros (NEAB); Núcleo de Estudos de Gênero e Diversidades (NEGED). E-mail: silvanisvalentim@gmail.com

iD http://orcid.org/0000-0002-5798-2477

\section{Jane Moreira}

Mestra em Educação Tecnológica, CEFET-MG; Núcleo de Pesquisa e Estudos AfroBrasileiros. Graduada em Letras, Pós Graduada em Educação das Relações Étnico Raciais e Educação em Direitos Humanos pela UFPR; Especialização em Gestão de Políticas Públicas em Gênero e Raça pela UFMG, professora de Língua Portuguesa na rede municipal de Sabará e na rede estadual de Minas Gerais. E-mail: janevida20111@hotmail.com

(iD http://orcid.org/0000-0002-9023-6951 